\title{
PERBANDINGAN HASIL EKSPERIMEN SUPERPOSISI GELOMBANG BUNYI BONANG BARUNG SECARA SIMULTAN DAN MIXING BERBANTUAN AUDACITY DAN MATLAB
}

\author{
Lusi Widayanti ${ }^{1, \mathrm{a})}$, Yudhiakto Pramudya ${ }^{2, \mathrm{~b})}$ \\ ${ }^{1}$ HSBC, Jl. Jend. Sudirman WTC 1, Jakarta dan 12920 \\ ${ }^{2}$ Jl. Pramuka Umbulharjo, Yogyakarta dan 55164
}

Email: a)widalusi@ymail.com, b)ypramudya.uad@gmail.com

\begin{abstract}
Abstrak
Bonang dapat dimainkan secara simultan dari dua nada yang sama dengan satu oktaf terpisah, sehingga muncul fenomena superposisi. Untuk mengamati perbedaan dalam waveform dan spektrum superposisi untuk berbagai warna suara bonang barung, audacity digunakan dalam penelitian ini untuk merekam dan menganalisis bunyi bonang barung. Perangkat lunak MATLAB digunakan untuk mengolah data dari domain waktu ke domain frekuensi. Objek penelitian adalah satu set bonang barung laras pelog Gending Bahana yang terbuat dari besi. Pencon bonang barung dipukul secara terpisah dan dipukul secara simultan. Hasil rekaman bonang barung yang dipukul secara terpisah kemudian di-mix dengan fasilitas mix and render pada audacity. Kemudian dianalisis dengan spektrum plot dan menghasilkan nilai frekuensi dasar dan frekuensi-frekuensi harmonik. Selain dianalisis dengan menu analisis pada audacity, hasil rekaman bunyi bonang barung dapat dianalisis dengan program FFT pada perangkat lunak MATLAB. Perbandingan hasil superposisi mix dengan superposisi simultan dengan audacity persentasenya berkisar dari $0 \%$ sampai dengan $2 \%$, sedangkan perbandingan hasil analisis superposisi dengan program pada MATLAB persentasenya berkisar dari $0 \%$ sampai dengan $0,4 \%$. Perbedaan frekuensi superposisi dengan audacity dan MATLAB terjadi karena MATLAB dapat menambahkan suara yang sangat rendah. Hasil superposisi yang diperoleh dari hasil mix dan simultan nilainya masih berada pada rentang yang hampir sama. Sehingga pada saat dipukul, hasil superposisi mix dan simultan akan terdengar sama oleh orang yang mendengarnya karena frekuensi dan amplitudonya hampir sama meskipun terdapat beda fase.
\end{abstract}

Kata Kunci: audacity, bonang barung, FFT, MATLAB, dan Superposisi.

\begin{abstract}
Bonang can be played simultaneously on the same two-tone one octave apart, so it appears the phenomenon of superposition. To observe the differences in superposition waveform and spectrum of various timbres of bonang barung, the audacity software was employed. It is used to record and analyse the sound bonang barung, and MATLAB software to process data from the time domain to the frequency domain. The object of research is a set pelog bonang barung Gending Bahana made of iron. The research was conducted by recording of bonang barung sounds using software audacity. Pencon bonang barungs were beaten separately and simultaneously. The recorded sound of bonang barung that is beaten separately then mixed with mix and rendering facilities in audacity. Then the recorded sounds analyzed by spectral plots for producing the fundamental and harmonic frequencies. Besides analyzed with analysis menu on audacity, recordings of sound bonang barung can be analyzed with FFT program in MATLAB software. The results showed that comparison of the results of mix and simultaneous superposition with audacity percentage ranged from $0 \%$ to $2 \%$, while the comparison of the results of superposition analysis with MATLAB program on the percentage ranged from $0 \%$ to $0,4 \%$.
\end{abstract}


Superposition results obtained from the mix and simultaneous value remained at almost the same range. So that when struck, mix and simultaneous superposition result will sound the same by those who hear it because of the frequency and the amplitude is almost as though there is a phase difference.

Keywords: audacity, bonang barung, FFT, MATLAB, and superposition.

\section{PENDAHULUAN}

Salah satu alat musik tradisional yang memiliki karakteristik bunyi tersendiri yaitu gamelan [1]. Gamelan memiliki karakteristik bunyi yang berbeda, hal ini disebabkan karena proses penalaan yang dilakukan masih bersifat subjektif [2].

Untuk merekam dan menganalisis karakteristik akustik instrumen Gamelan digunakan perangkat lunak audacity. Perangkat lunak audacity dapat merekam sinyal suara, menampilkan dan mengukur frekuensi, dan mengukur spektrum frekuensi warna bunyi serta dapat digunakan dalam pembelajaran fisika. Pada perangkat lunak audacity terdapat fasilitas analisis transformasi fourier, sehingga dapat menampilkan spektrum frekuensi secara visual dan numerik [3].

Audacity digunakan untuk mengamati perbedaan dalam bentuk gelombang dan spektrum superposisi untuk berbagai warna nada dari bonang barung. Saat pengolahan sinyal dengan analisis spektrum pada audacity terjadi transformasi sinyal yang awalnya dalam domain waktu kemudian diubah ke dalam domain frekuensi. Proses transformasi tersebut dapat diolah dengan menggunakan Fast Fourier Transform (FFT). Penelitian ini akan membahas fungsi FFT hasil superposisi gelombang bunyi bonang barung berbantuan audacity dan MATLAB.

\section{METODE PENELITIAN}

Penelitian ini dilaksanakan di Ruang Auditorium Kampus 1, Universitas Ahmad Penelitian dilakukan pada malam hari mulai jam 20.30 sampai selesai. Penelitian dilakukan pada malam hari untuk mengurangi kebisingan, karena ruangan yang digunakan untuk merekam bunyi bonang barung bukan ruang kedap suara. Alat yang digunakan dalam penelitian ini adalah perangkat keras dan perangkat lunak berupa perangkat lunak Audacity versi 2.0.5. Perangkat lunak MATLAB versi 7.6.0.324 (R2008a), laptop Compaq 510 T5870 Intel Core 2 Duo @2.00GHz, mikrofon jepit merk TOA ZM-360, serta satu set pelog bonang barung Gending Bahana.

Dalam penelitian ini langkah awal dilakukan dengan merekam bunyi bonang barung dengan menggunakan Audacity. Pada saat merekam bunyi bonang barung, laptop berpindah mengikuti posisi pencon.

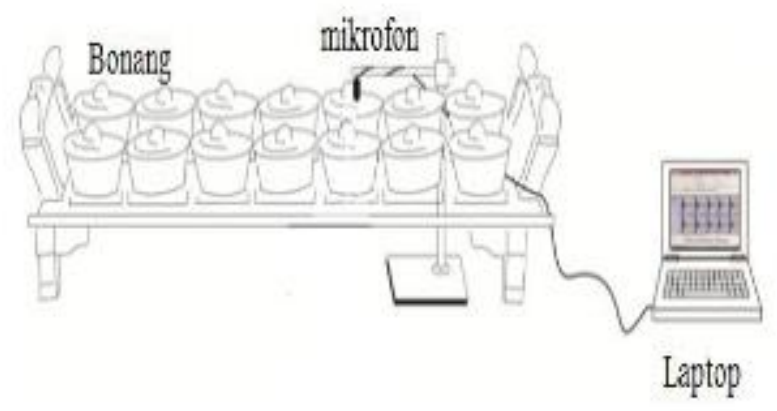

GAMBAR 1. Skema rangkaian alat penelitian.

Rekaman suara audacity diekspor dan disimpan dalam bentuk wav. Hasil rekaman dibaca oleh MATLAB dan dieksekusi.

Untuk mengetahui nilai perbandingan hasil superposisi simultan dan superposisi mix dilakukan perhitungan dengan menggunakan persamaan (1) sebagai berikut:

$$
\text { Perbandingan }=\left|\frac{\text { simultan }- \text { mix }}{\operatorname{mix}}\right| \times 100 \%
$$




\section{HASIL DAN PEMBAHASAN}

\section{Perbandingan hasil superposisi bonang barung yang dipukul secara simultan dan di-mix menggunakan audacity}

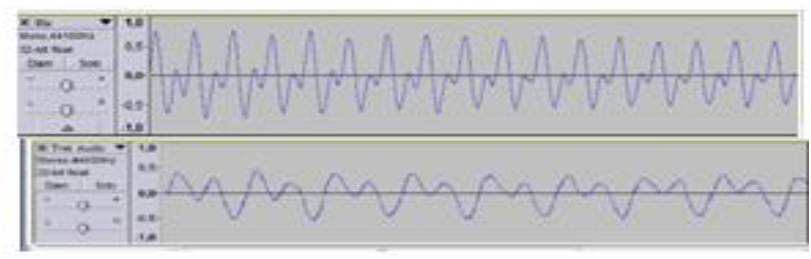

GAMBAR 2. (a) hasil rekaman nada pertama yang di-mix dengan audacity dan (b) hasil rekaman nada pertama yang dipikul secara simultan

Bentuk gelombang hasil superposisi yang dipukul secara terpisah pada gambar 2 (a) maupun dipukul secara simultan pada gambar 2 (b) terlihat berbeda, namun pada dasarnya terdengar sama. Dengan analogi, spektrum gelombang hasil superposisi mix dan simultan adalah identik karena terbentuk dari gelombang sinus dengan frekuensi dan amplitudo yang hampir sama.

Frekuensi dasar nada pertama superposisi mix pada gambar 3 (a) sebesar $301 \mathrm{~Hz}$ dan amplitudo bunyi sebesar -16,7 dBFS. Sedangkan frekuensi dasar nada pertama superposisi simultan diperoleh hasil yang sama yaitu sebesar $301 \mathrm{~Hz}$ dengan amplitudo bunyi -15,6 dBFS. Pada saat dua gelombang dijumlahkan akan ada dua frekuensi yang muncul dan hasilnya berupa kelipatannya. Hasil superposisinya dapat dilihat pada tabel 1 .

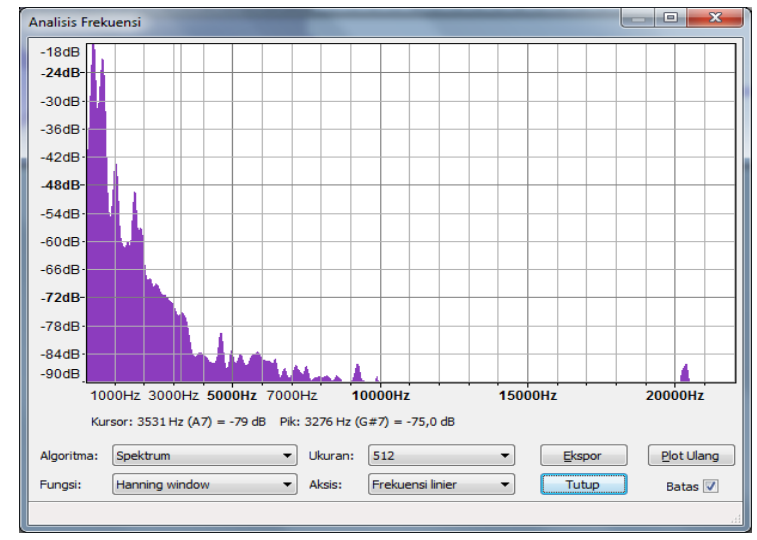

(a)

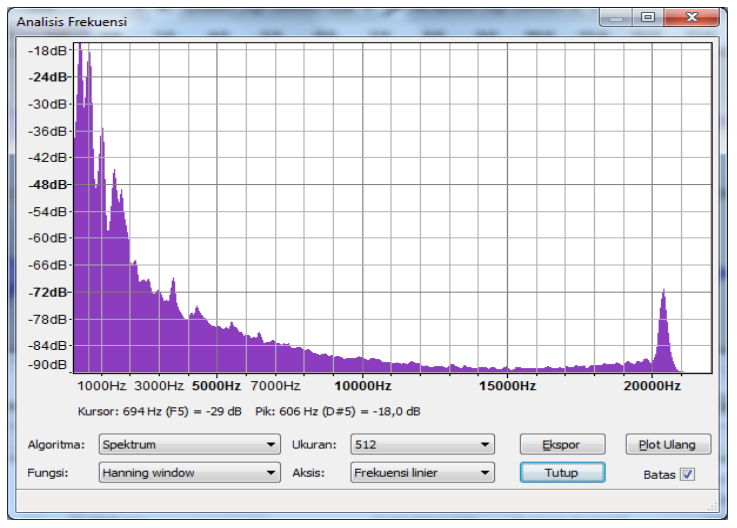

(b)

GAMBAR 3. (a) Spektrum nada pertama yang dipukul secara terpisah dan di-mix dengan audacity dan (b) spektrum nada pertama yang dipukul secara simultan

Superposisi mix adalah hasil mix dengan menggunakan audacity dari dua sumber bunyi yantu deret pertama dan deret kedua untuk nada yang sama. Pada saat di-mix terdapat beberapa frekuensi harmonik, misalnya pada nada pertama harmonik pertama $301 \mathrm{~Hz}$ harmonik kedua frekuensinya $609,6 \mathrm{~Hz}$. Hal tersebut menunjukkan bahwa harmonik pertama dan harmonik kedua dan seterusnya muncul frekuensi baik frekuensi nada rendah maupun nada tinggi. Namun intensitasnya tidak selalu sama saat dipukul secara terpisah maupun secara simultan karena terjadi subjektivitas pemukulan pencon.

Perbandingan hasil superposisi mix dan superposisi simultan menunjukkan hasil yang hampir sama baik untuk harmonik pertama, harmonik kedua dan seterusnya. Ketika digunakan perintah mix and render, semua perintah editing dan pencampuran akan dilakukan pada sinyal suara, serta karena proses penjumlahan yang terjadi ketika dua gelombang tersebut di-mix. Hal ini menyebabkan perbedaan antara frekuensi hasil superposisi mix dan superposisi simultan. Perbandingan hasil superposisi mix dengan superposisi simultan persentasenya berkisar dari $0 \%$ sampai dengan $2 \%$. 
Tabel 1. Perbandingan frekuensi dan amplitudo bonang barung untuk superposisi yang di-mix dan yang dipukul secara simultan dengan bantuan Audacity

\begin{tabular}{clcccc}
\hline \multirow{2}{*}{ Nada } & \multicolumn{2}{c}{ Harmonik 1 } & \multicolumn{2}{c}{ Harmonik 2 } \\
\cline { 3 - 6 } & $\boldsymbol{f ( H z )}$ & $\begin{array}{c}\text { Amplitudo } \\
(\mathbf{d B F S})\end{array}$ & $\boldsymbol{f ( H z )}$ & $\begin{array}{c}\text { Amplitudo } \\
(\mathbf{d B F S})\end{array}$ \\
\hline \multirow{2}{*}{1} & Superposisi mix & 301,0 & $-17,7$ & 609,6 & $-20,5$ \\
& Superposisi simultan & 301,0 & $-15,6$ & 604,5 & $-18,3$ \\
2 & Superposisi mix & 325,3 & $-17,3$ & 652,4 & $-17,8$ \\
& Superposisi simultan & 324,1 & $-17,6$ & 651,7 & $-22,8$ \\
\multirow{2}{*}{3} & Superposisi mix & 359,6 & $-16,1$ & 707,7 & $-18,7$ \\
& Superposisi simultan & 360,2 & $-16,2$ & 708,3 & $-18,2$ \\
\multirow{2}{*}{4} & Superposisi mix & 408,3 & $-14,7$ & 822,6 & -21 \\
& Superposisi simultan & 408,7 & $-18,3$ & 823,7 & $-19,4$ \\
5 & Superposisi mix & 456,6 & $-19,6$ & 886,3 & $-21,4$ \\
& Superposisi simultan & 456,1 & $-20,1$ & 885,1 & $-23,8$ \\
6 & Superposisi mix & 474,6 & $-18,2$ & 953,0 & $-20,3$ \\
& Superposisi simultan & 474,0 & $-18,5$ & 954,2 & $-19,2$ \\
7 & Superposisi mix & 513,8 & $-18,1$ & 1049 & $-20,8$ \\
& Superposisi simultan & 524,1 & $-20,1$ & 1048 & $-22,4$ \\
\hline
\end{tabular}

Perbandingan hasil superposisi bonang barung yang dipukul secara simultan dan di-mix menggunakan MATLAB

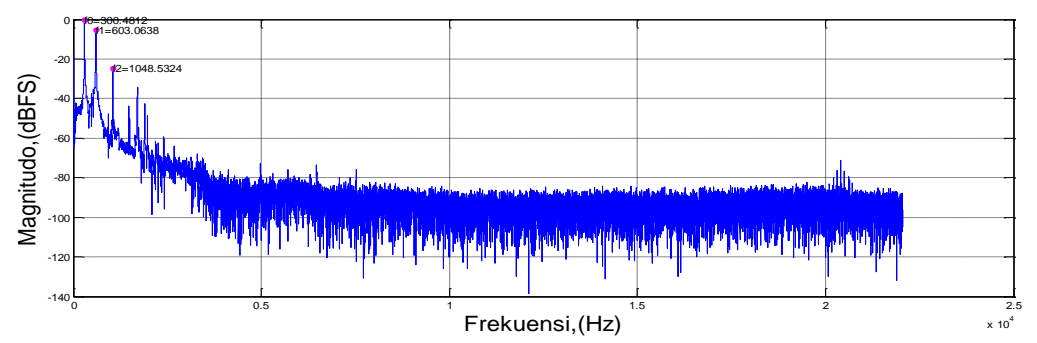

GAMBAR 4. Grafik nada pertama superposisi mix hasil analisis FFT

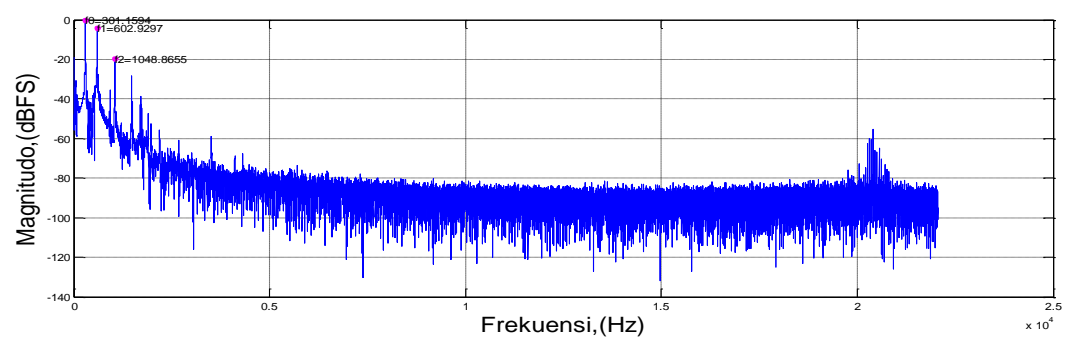

GAMBAR 5. Grafik nada pertama superposisi simultan hasil analisis FFT

Hasil analisis superposisi mix dan superposisi simultan dapat dilihat pada gambar 4 dan gambar 5 . Frekuensi yang dihasilkan dari superposisi mix pada tabel 2 sebesar $300,5 \mathrm{~Hz}$ dan $603,1 \mathrm{~Hz}$. Sedangkan hasil superposisi simultan nilainya $301,2 \mathrm{~Hz}$ dan $602,9 \mathrm{~Hz}$. Hasil superposisi yang diperoleh dari hasil mix dan simultan nilainya tidak terlalu berbeda. Masih berada pada rentang yang hampir sama, yaitu $300 \mathrm{~Hz}-310 \mathrm{~Hz}$. 
Tabel 2. Perbandingan frekuensi dan amplitudo bonang barung untuk superposisi yang di-mix dan yang dipukul secara simultan dengan bantuan MATLAB

\begin{tabular}{|c|c|c|c|c|c|}
\hline & \multirow[b]{2}{*}{ Nada } & \multicolumn{2}{|c|}{ Harmonik 1} & \multicolumn{2}{|c|}{ Harmonik 2} \\
\hline & & $f(\mathbf{H z})$ & $\begin{array}{c}\text { Amplitudo } \\
\text { (dBFS) }\end{array}$ & $f(\mathbf{H z})$ & $\begin{array}{c}\text { Amplitudo } \\
\text { (dBFS) }\end{array}$ \\
\hline \multirow[t]{2}{*}{1} & Superposisi mix & 300,5 & 0 & 603,1 & $-5,41$ \\
\hline & Superposisi simultan & 301,2 & 0 & 602,9 & $-4,31$ \\
\hline \multirow[t]{2}{*}{2} & Superposisi mix & 335,1 & 0 & 657,5 & $-3,57$ \\
\hline & Superposisi simultan & 335,3 & 0 & 657,8 & $-6,47$ \\
\hline \multirow[t]{2}{*}{3} & Superposisi mix & 355,8 & 0 & 700,3 & $-4,39$ \\
\hline & Superposisi simultan & 355,8 & 0 & 700,3 & $-3,13$ \\
\hline \multirow[t]{2}{*}{4} & Superposisi mix & 417,3 & 0 & 828,6 & $-4,07$ \\
\hline & Superposisi simultan & 419,1 & 0 & 829,0 & $-1,18$ \\
\hline \multirow[t]{2}{*}{5} & Superposisi mix & 456,1 & 0 & 883,4 & $-3,60$ \\
\hline & Superposisi simultan & 455,7 & 0 & 881,9 & $-1,68$ \\
\hline \multirow[t]{2}{*}{6} & Superposisi mix & 477,5 & 0 & 944,2 & $-2,73$ \\
\hline & Superposisi simultan & 477,6 & 0 & 944,9 & $-3,48$ \\
\hline \multirow[t]{2}{*}{7} & Superposisi mix & 514,3 & 0 & 1041 & $-0,73$ \\
\hline & Superposisi simultan & 515,7 & 0 & 1042 & $-0,98$ \\
\hline
\end{tabular}

Perbandingan frekuensi hasil penelitian ini dengan penelitian Suryodiningrat, dkk. sebesar $1,163 \%$. Frekuensi superposisi yang diperoleh dari perangkat lunak audacity dan MATLAB menghasilkan hasil yang hampir sama misalnya pada frekuensi dasar nada pertama deret pertama yaitu sebsar $301 \mathrm{~Hz}$, meskipun terlihat ada perbedaan besar amplitudonya. Sehingga pada saat dimainkan, hasil superposisi mix dan simultan secara visualisasi terdapat beda fase namun akan terdengar sama oleh orang yang mendengarnya karena persepsi bunyi yang ditangkap oleh gendang telinga frekuensi dan amplitudonya hampir sama. Perbandingan hasil superposisi mix dengan superposisi simultan dengan audacity persentasenya berkisar dari $0 \%$ sampai dengan $2 \%$, sedangkan perbandingan hasil analisis superposisi dengan program pada MATLAB persentasenya berkisar dari $0 \%$ sampai dengan $0,4 \%$.

\section{SIMPULAN}

Perbandingan hasil superposisi mix dengan superposisi simultan dengan audacity persentasenya berkisar dari $0 \%$ sampai dengan $2 \%$, sedangkan perbandingan hasil analisis superposisi dengan program pada MATLAB persentasenya berkisar dari $0 \%$ sampai dengan $0,4 \%$. Perbedaan frekuensi superposisi dengan audacity dan MATLAB terjadi karena MATLAB dapat menambahkan suara yang sangat rendah. Hasil superposisi yang diperoleh dari hasil mix dan simultan nilainya masih berada pada rentang yang hampir sama. Sehingga pada saat dipukul, hasil superposisi mix dan simultan akan terdengar sama oleh orang yang mendengarnya karena frekuensi dan amplitudonya hampir sama meskipun terdapat beda fase. Namun karena telinga manusia hanya peka terhadap frekuensi dan amplitudo sehingga hasil superposisi simultan dan mix sama.

\section{REFERENSI}

[1] W. A. Sethares, Tuning, Timbre, Spectrum, Scale. Second Edition, London, Springer (2005), p. 379-380.

[2] Suyatno, H. A. Tjokronegoro, IGN. Merthayasa, dan R. Supanggah, Karakteristik Akustik Gamelan Jawa Studi Kasus Gamelan Milik PSTK ITB. Prosiding Seminar Fisika dan Aplikasinya( 2013). ISSN: 2086-0773. 
[3] Ishafit. Teknologi Informasi dan Komunikasi dalam Pembelajaran Fisika: Komputerisasi Eksperimen Bunyi Berbasis Soundcard Laptop. Prosiding Seminar Nasional Fisika UNJ (2012). 